\title{
Relationship between lightning and model simulated microphysical parameters over the central and eastern Mediterranean
}

\author{
D. K. Katsanos, K. Lagouvardos, and V. Kotroni \\ National Observatory of Athens, Institute for Environmental Research and Sustainable Development, Athens, Greece
}

Received: 15 April 2009 - Revised: 4 September 2009 - Accepted: 21 September 2009 - Published: 21 October 2009

\begin{abstract}
In this study the relationship between lightning and simulated microphysical parameters of clouds, is examined. In order to investigate such a relationship, a number of cases with significant lightning activity that occurred during the wet period of the year over the central and eastern Mediterranean have been selected, based on the lightning activity reported by the ZEUS lighting detection network, operated by the National Observatory of Athens. For the same cases, simulations with the non-hydrostatic MM5 model were performed with the aim of reproducing the dynamical and microphysical parameters associated with the weather systems that produced lightning. The analysis showed that the temporal distribution of convective rainfall is not well correlated with that of lightning, while on the contrary, the temporal distribution of the simulated concentrations of solid hydrometeors correlates well with lightning and there is also a general coincidence of their maxima. Further, it was shown that the best correlation was found during the development stage of the storms, while during the decay phase the number of lightning decreases much faster that the simulated concentrations of solid hydrometeors.
\end{abstract}

\section{Introduction}

The Mediterranean Sea, although a relatively small and rather warm body of water, is considered as one of the most important centers of electrical activity in the northern hemisphere during the cold period of the year, as this is implied by the studies made by Orville (1981), Christian et al. (1999) and Holt et al. (2001). In more recent studies, Price and Federmesser (2006) based on TRMM satellite data over the Mediterranean, concluded that more than $75 \%$ of rain and

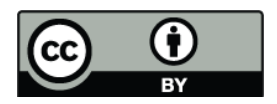

Correspondence to: D. K. Katsanos (katsanos@meteo.noa.gr) lightning in the region occur during the period from October to March, while more than $90 \%$ of the thunderstorms occur over the sea. Furthermore, lightning activity presents its maximum during November, while the maximum of precipitation occurs during December. In a recent study, Katsanos et al. (2007a) have shown that during the wet period of the year (e.g. autumn and winter for the area of the Mediterranean) the lightning activity occurs over the maritime area and near the coasts almost delineating the Mediterranean coastline.

The significant atmospheric electrical activity over the Mediterranean Sea, has motivated many researchers to investigate, among other issues, the relationship between lightning and parameters such as rainfall, or microphysical characteristics of clouds. In a number of studies devoted to the investigation of the relationship between lightning activity and microphysical parameters of clouds, such as those by Toracinta and Zipser (2001), Defer et al. (2005) and Katsanos et al. (2007b), satellite measurements in the microwave region of the spectrum, and especially measurements in the $85 \mathrm{GHz}$ frequency, have been used. According to our present understanding of microphysical charging mechanisms, the presence of ice particles is a necessary component for the electrification processes within clouds that lead to lightning occurrence (Rakov and Uman, 2003). Also, strong updrafts can activate aerosols and enhance homogeneous freezing in order to produce more cloud particles near the top of the cloud. Thus, lighting activity seems to be related to the amount of small ice that is present at the cloud top (Sherwood et al., 2006). According to Deierling and Petersen (2008) the presence of a large amount of hydrometeors in the mixed ice phase region, produced by "high" updraft speeds, computed by ground - based and dual polarimetric radar observations, results to higher number of collisions between graupel and ice crystals with subsequent charge separation that can lead to lightning production. Also, they found that there is a strong correlation between precipitation ice mass and mean total lightning activity.

Published by Copernicus Publications on behalf of the European Geosciences Union. 
In these studies it was shown that low values of brightness temperature are associated with lightning activity and therefore this kind of data could be used as proxies for estimating the possibility of lightning occurrence. Recently Pessi and Businger (2009) showed a very good correlation between satellite estimated convective rainfall, derived by the Precipitation Radar (PR) onboard TRMM that measures at $13.8 \mathrm{GHz}$ and lightning, giving motivation to investigate the possibility of a relationship between those two parameters. Most of the studies that investigate the relationship between convective precipitation and lightning, are devoted to tropical thunderstorms, while there is a lack of such studies over the Mediterranean.

Since satellites can only provide data during their overpass above a specific area, it is difficult to cover adequately all cases that occur and to study their temporal evolution. As direct measurements of ice content are sparse, this analysis could be based on simulated fields provided by mesoscale atmospheric numerical models, as discussed in the following section. Such an approach was recently used by Lagouvardos and Kotroni (2007) concluding that spaceborne measurements can be used for the observation of mid-latitude weather systems as well as for the validation of high resolution model results.

The rest of the paper is organized as follows: Sect. 2 presents the data and the methodology used, while Sect. 3 discusses the comparison between MM5 model simulated fields and lightning activity. Section 4 is devoted to the concluding remarks and prospects of this study.

\section{Data and methodology}

\subsection{Lightning Data}

The analysis and the selection of cases are based on lightning data provided by the ZEUS network and simulations performed with the non-hydrostatic model MM5. A number of cases, most of them lasting one day, with significant amount of recorded lightning flashes by ZEUS during autumn and winter (2005-2008) over the central and eastern Mediterranean, were selected in order to perform the comparison with the simulated fields by MM5.

The ZEUS long-range lightning detection system, operated by the National Observatory of Athens, is based on detection of sferics - the impulsive radio noise emitted by a lightning strike - in the Very Low Frequency (VLF) spectrum between 7 and $15 \mathrm{kHz}$. The ZEUS system consists of a network of six VLF receivers located around the periphery of Europe (Birmingham in UK, Roskilde in Denmark, Iasi in Romania, Larnaka in Cyprus, Athens in Greece and Lisbon in Portugal). Each receiver reports the vertical electric field as a function of time which represents the sferic's waveform and includes a time stamp synchronized to GPS time. At each receiver site an identification algorithm is executed that detects a probable sferics candidate, excludes weak signal and noise and is capable of capturing up to 70 sferics per second. Then the lightning location is retrieved (at the central station of the network) using the arrival time difference triangulation technique. Further details on ZEUS network are given in Kotroni and Lagouvardos (2008).

The detection efficiency and location error of the ZEUS lightning detection network has been evaluated recently against collocated data provided by the LINET detection network (Lagouvardos et al., 2009). The area of comparison was limited over a part of Central-Western Europe, where the dense LINET network can guarantee a high detectability of lightning strokes with location accuracy of the order of a few hundred meters. The analysis showed that the location error of ZEUS was calculated to be $\sim 6.8 \mathrm{~km}$, while the detection efficiency was $\sim 25 \%$, with a characteristic under-prediction during nighttime.

\subsection{MM5 model configuration}

The MM5 model is a non-hydrostatic, primitive equations model (Dudhia, 1993). Several physical parameterization schemes, are available in the model for the boundary layer, the radiative transfer, the microphysics and the cumulus convection. For this study, from the multitude of available schemes the following have been selected: the scheme by Hong and Pan (1996) for the boundary layer, the KainFritsch (1993) for cumulus convection and the Schultz (1995) for explicit microphysics. The last two schemes have been proved to provide the most skillful precipitation forecasts in the eastern Mediterranean (Kotroni and Lagouvardos, 2001).

Two domains are used for the model simulations. The coarse domain covers most of Europe, up to $60^{\circ} \mathrm{N}$, North Africa and the Middle East with a horizontal resolution of $24 \mathrm{~km}$ and $220 \times 140$ grid points. The inner domain covers a part of the central and eastern Mediterranean with a horizontal resolution of $8 \mathrm{~km}$ and $220 \times 148$ grid points. In the vertical, 31 sigma levels are defined from the surface up to $100 \mathrm{hPa}$. ECMWF analyses at 0.5 degrees resolution have been used to initialize the model and to nudge the boundaries of the coarse domain during the simulation period.

In a recent study, Katsanos et al. (2008) presented the first results of a case simulated by MM5 model, showing that there is a good agreement between forecasted fields of ice phase cloud elements and lightning activity, mostly regarding their temporal evolution. These results gave the motivation for a further study. The output fields that are used for the comparison in the present study are the vertically integrated mixing ratios of ice, snow and graupel, the rainfall, both total and convective. Each simulation is initialized at 00:00 UTC and lasts $24 \mathrm{~h}$, and for some exceptions $48 \mathrm{~h}$, with outputs at 1-h intervals. Ten cases with significant lightning activity, mainly in the central Mediterranean, which occurred from 2005 to 2008, have been simulated. The selection of cases was based on the number of daily lightning flashes observed 
over the maritime area of central and eastern Mediterranean. The selected days satisfied a criterion of at least $20000 \mathrm{ob}-$ served lightning flashes over the selected area, during $24 \mathrm{~h}$. Among these ten cases, for six cases the model was able to reproduce well the temporal and spatial evolution of the weather system, in accordance with ZEUS lightning observations. In the following paragraphs two representative cases with heavy rainfall and intense lightning are presented in detail, later on, all six cases are discussed. It should be mentioned that the four remaining cases that are not analyzed in the following have been considered as not successful simulations, as they failed to reproduce a convective activity coherent (both spatially and temporally) with the observations.

\section{Results - discussion}

\subsection{Case study (a)}

On 13 December 2005 at 06:00 UTC, a barometric low with a central pressure of $1005 \mathrm{hPa}$ was located over the area northwest of the Gulf of Sidra. The pressure low deepened to $997 \mathrm{hPa}$ at 12:00 UTC, and reached the lowest central pressure of $992 \mathrm{hPa}$ by the end of the day, just offshore the Tunisian coast. The pressure low was accompanied by a cold front moving slowly northeastwards. Within $24 \mathrm{~h}$ an amount of almost $35000 \mathrm{CG}$ lightning flashes was recorded. The corresponding TRMM overpass showed a band of low Polarization Corrected Temperature (PCT) values (not shown) expanding from Sicily southwards to the Sidra Gulf denoting the cold front position.

Figure 1a presents the convective precipitation (in $\mathrm{mm}$ ) with the surface pressure (in hPa), as simulated by the MM5 model inner grid (the domain shown represents the extent of MM5 inner domain with $8-\mathrm{km}$ resolution), at 12:00 UTC. The simulated low pressure centre of $996 \mathrm{hPa}$ is located southwest of Sicily. The model has positioned the low pressure centre almost $1^{\circ}$ to the west of its actual position. Significant lightning activity was recorded during the event (Fig. 1b). The convective precipitation field shows that rainfall and lightning are present in the same area during the same time period; however convective rain is still forecasted in areas that no lightning activity is recorded. The highest concentrations of simulated solid hydrometeors (not shown) were found shifted to the west of the area where lightning activity was recorded by ZEUS system.

Figure 1c presents the cross section of the vertical velocity (in $\mathrm{ms}^{-1}$ ) along the $35^{\circ} \mathrm{N}$ latitude line and from $12^{\circ} \mathrm{E}$ to $18^{\circ} \mathrm{E}$ shown in Fig. 1b. It can be seen that updrafts are present in the same area where also lightning is recorded.

Figure 1d shows the vertical distribution of all ice phase elements (ice + graupel + snow) and only graupel separately across the same line as in Fig. 1c. It is shown that ice particles are present down to relatively low levels $(800 \mathrm{hPa})$, with graupel (black contour line) being the dominant hydrome- teor at the lower levels of the cloud. Ice on the other hand, is mostly present at the upper levels of the cloud (not shown).

The temporal evolution of the lightning activity with the convective precipitation and ice particle concentrations, are presented in the following. This is done by integrating both fields within a box with dimensions $5^{\circ} \times 5^{\circ}$ including the area from $11^{\circ} \mathrm{E}$ to $16^{\circ} \mathrm{E}$ and from $33.5^{\circ} \mathrm{N}$ to $38.5^{\circ} \mathrm{N}$ (denoted with a dotted box in Fig. 1b) in order to account for the "shift" of the simulated fields. Within this box, the number (sum) of lightning flashes was calculated along with the maximum values of convective rainfall and the average profile of the integrated mixing ratio of ice+graupel+snow, derived from the MM5 simulations.

The results concerning the comparison between convective precipitation and lightning, are shown in Fig. 1e. It can be seen that there is coherence in the temporal evolution of lightning activity and model calculated convective precipitation up to 15:00 UTC, with coincidence of the time of both maxima, but also coherence in the decrease of both fields from the time of their peak at 10:00 UTC up to the minima at 13:00 UTC. From 15:00 UTC and on, the two fields do not evolve in the same way as the lightning activity decreases further while, on the contrary, the convective precipitation increases. It is obvious that convective rainfall is present, according to the model forecasted fields, both before and after the period of lightning occurrence.

In Fig. If the comparison between the temporal evolution of the average profile of the integrated mixing ratio of ice + graupel + snow and lightning activity is presented, for the hours from 06:00 to 18:00 UTC. The mixing ratio presents almost a "bell" shaped distribution with the maximum values from 07:00 to 12:00 UTC, which coincides with the time interval of the fast low pressure deepening. As expected, the building up of the lightning activity time lags the increase in the mixing ratio of ice + snow + graupel, although here the time lag of about one to two hours is considered larger than what is usually observed. This is partly attributed to the fact that, while lightning observations are continuous, the model outputs are at hourly intervals and also to a delay of the model itself to reproduce the convective and microphysical properties of the event. Nevertheless, it should be noted that the two curves coincide at their maximum which occurs at 10:00 UTC. Then, within the period of decrease of the mixing ratio, the lightning activity also decreases with a faster rate. Unlike the comparison of the lightning with the convective precipitation, the temporal evolution of lightning actually seems to be very well correlated with the presence of the ice phase species.

\subsection{Case study (b)}

On 30 October 2006 at 06:00 UTC, a barometric low with a central pressure of $1003 \mathrm{hPa}$ was located over the region of the Aegean Sea, deepening throughout the day to $998 \mathrm{hPa}$, moving southwards and giving heavy rainfall in central and 

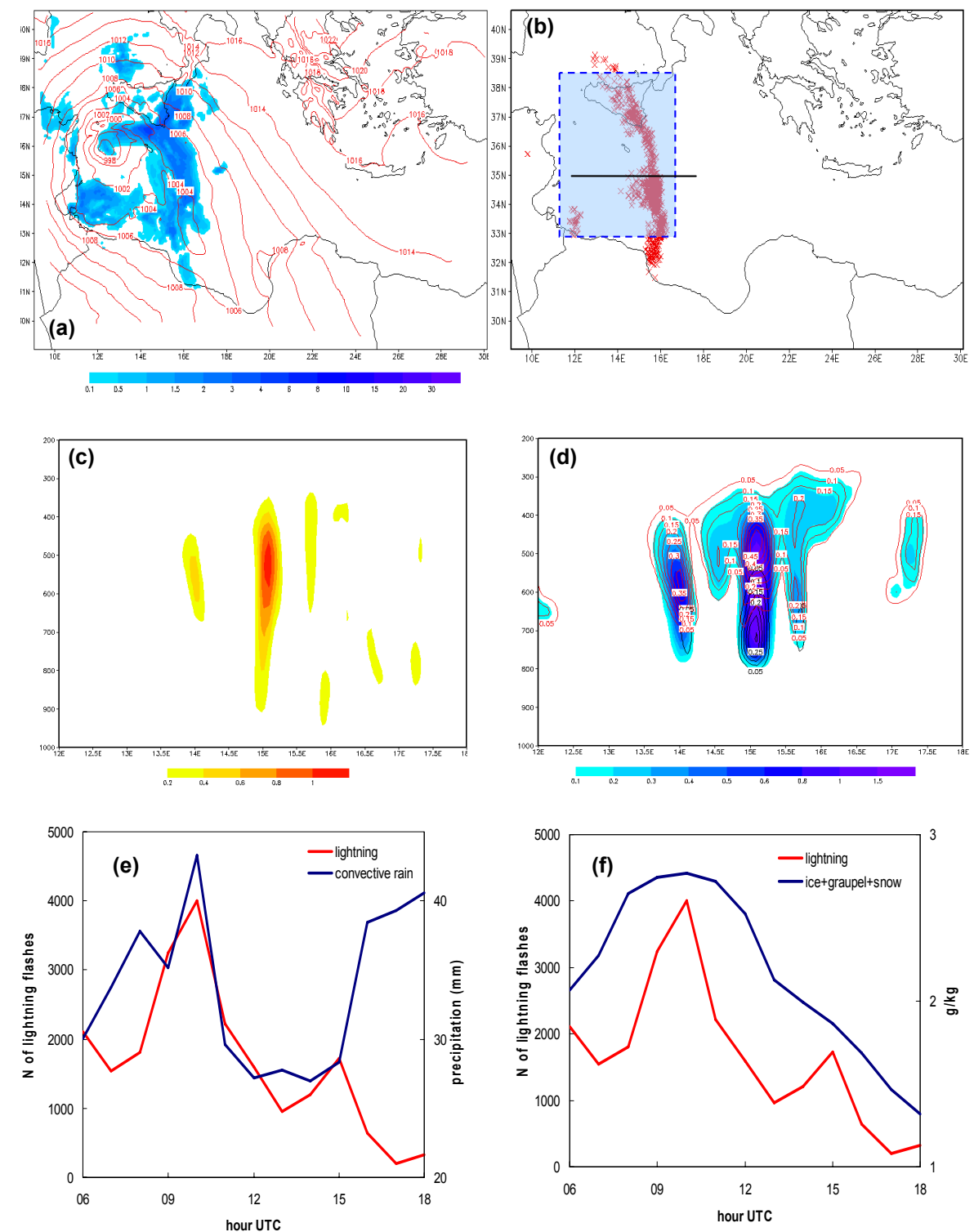

Fig. 1. (a) convective precipitation (mm) and surface pressure (in $\mathrm{hPa}$ with $2 \mathrm{hPa}$ interval) as forecasted by MM5 at 12:00 UTC, (b) lightning activity, (c) cross section (y axis in $\mathrm{hPa}$ ) of vertical velocity (in $\mathrm{ms}^{-1}$ with $0.2 \mathrm{~ms}^{-1}$ interval) across the line shown in (b), (d) cross section ( $\mathrm{y}$ axis in $\mathrm{hPa}$ ) of ice + graupel + snow (shaded), only graupel (black contour) and only ice (red contour) in $\mathrm{g} / \mathrm{kg}$, across the line shown in (b), temporal evolution of: (e) convective precipitation with lightning activity and (f) ice + graupel + snow with lightning activity, for the area within the box in (b).

eastern Greece, accompanied by a cold front. Within $24 \mathrm{~h}$ an amount of almost 22000 lightning flashes was recorded. Spatial comparison (Fig. 2a and b) shows the presence of simulated convective rainfall in areas without lightning activity. Indeed convective rainfall in this case is forecasted outspread in a large area, while lightning is recorded in a more limited area.

The cross section of forecasted vertical velocity (Fig. 2c) shows again the presence of updrafts in the area of lightning, however not very strong $\left(0.5 \mathrm{~ms}^{-1}\right)$ in comparison with the previous case. The vertical distribution of solid hydrometeors (Fig. 2d) shows that the model forecasts their presence in low levels, with graupel being again the dominant type at the lower parts of the cloud and snow or ice at the higher parts, with this distribution being favorable for creating charge separation necessary for cloud electrification and lightning occurrence.

The corresponding figure for the comparison of convective rainfall with lightning activity shows also a good agreement, regarding the forecast of rainfall at the same time that lightning is recorded (Fig. 2e), however as in the previous case, convective precipitation is forecasted before and after any lightning is observed. 

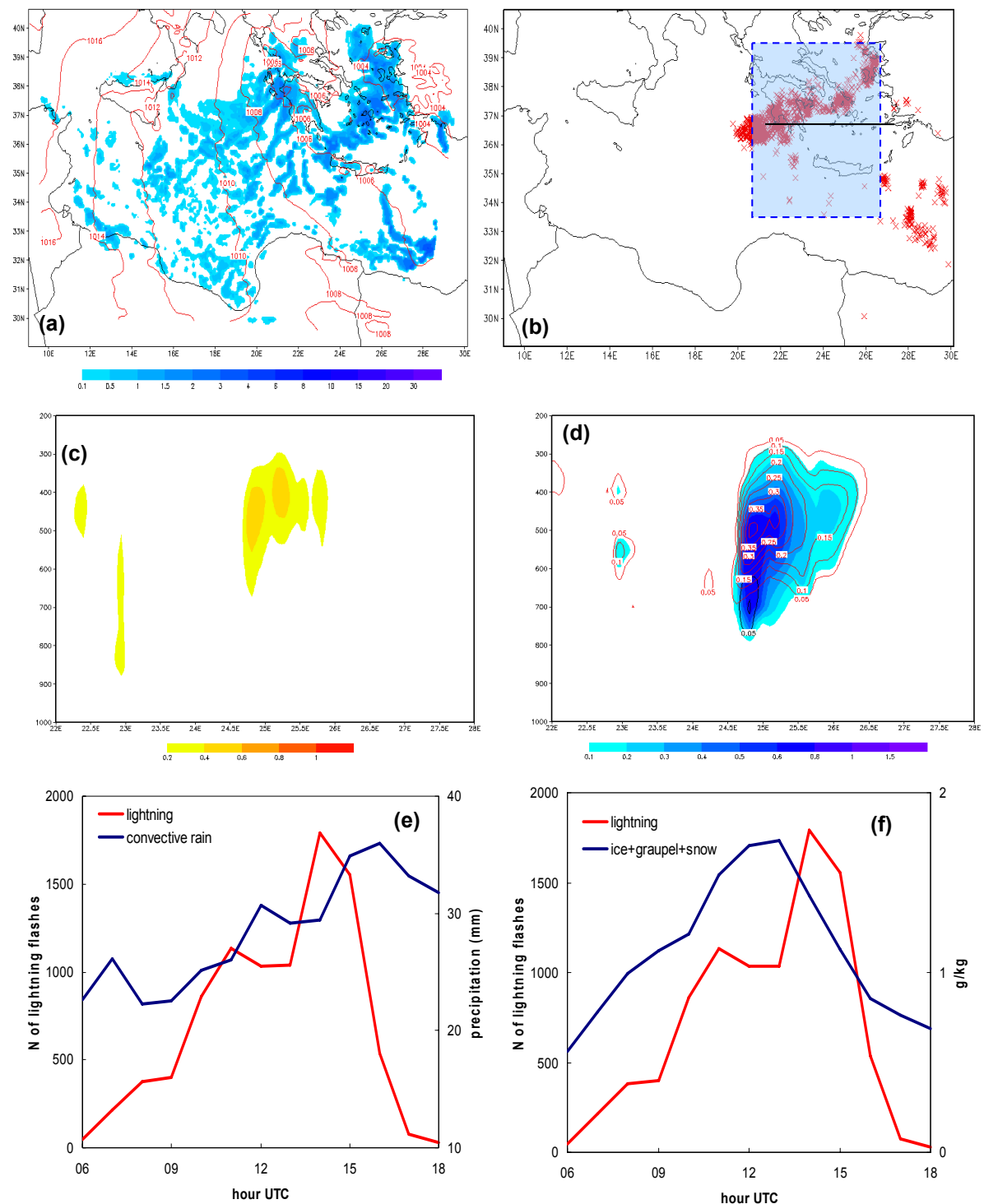

Fig. 2. (a) convective precipitation (mm) and surface pressure (in $\mathrm{hPa}$ with $2 \mathrm{hPa}$ interval) as forecasted by MM5 at 12:00 UTC, (b) lightning activity, (c) cross section ( $\mathrm{y}$ axis in $\mathrm{hPa}$ ) of vertical velocity (in $\mathrm{ms}^{-1}$ with $0.2 \mathrm{~ms}^{-1}$ interval) across the line shown in (b), (d) cross section (y axis in hPa) of ice + graupel + snow (shaded), only graupel (black contour) and only ice (red contour) in g/kg, across the line shown in (b), temporal evolution of: (e) convective precipitation with lightning activity and (f) ice + graupel + snow with lightning activity, for the area within the box in (b).

In agreement with the discussion of the previous case, there is also a very good agreement between the temporal variation of model integrated ice, graupel and snow with the amount of observed lightning flashes throughout the day (Fig. 2f), for the area delimited by the box shown in Fig. 2b, while there are slight differences in the occurrence times of the maximal values and in the rate of decrease, with the lightning activity decreasing more rapidly.

\subsection{Discussion}

In this section emphasis is given to the investigation of the correlation between the simulated solid hydrometeor concentrations and the observed lightning. For that purpose, the analysis is extended to all six cases and the results are shown in Figs. 3 and 4. All cases initially selected had more or less the same characteristics from a synoptic point of view: frontal depressions that developed over the sea, mainly during winter and autumn, which were moving eastwards affecting S. Italy and Greece with intense phenomena like thunderstorms with heavy rain and strong winds. For all cases, 

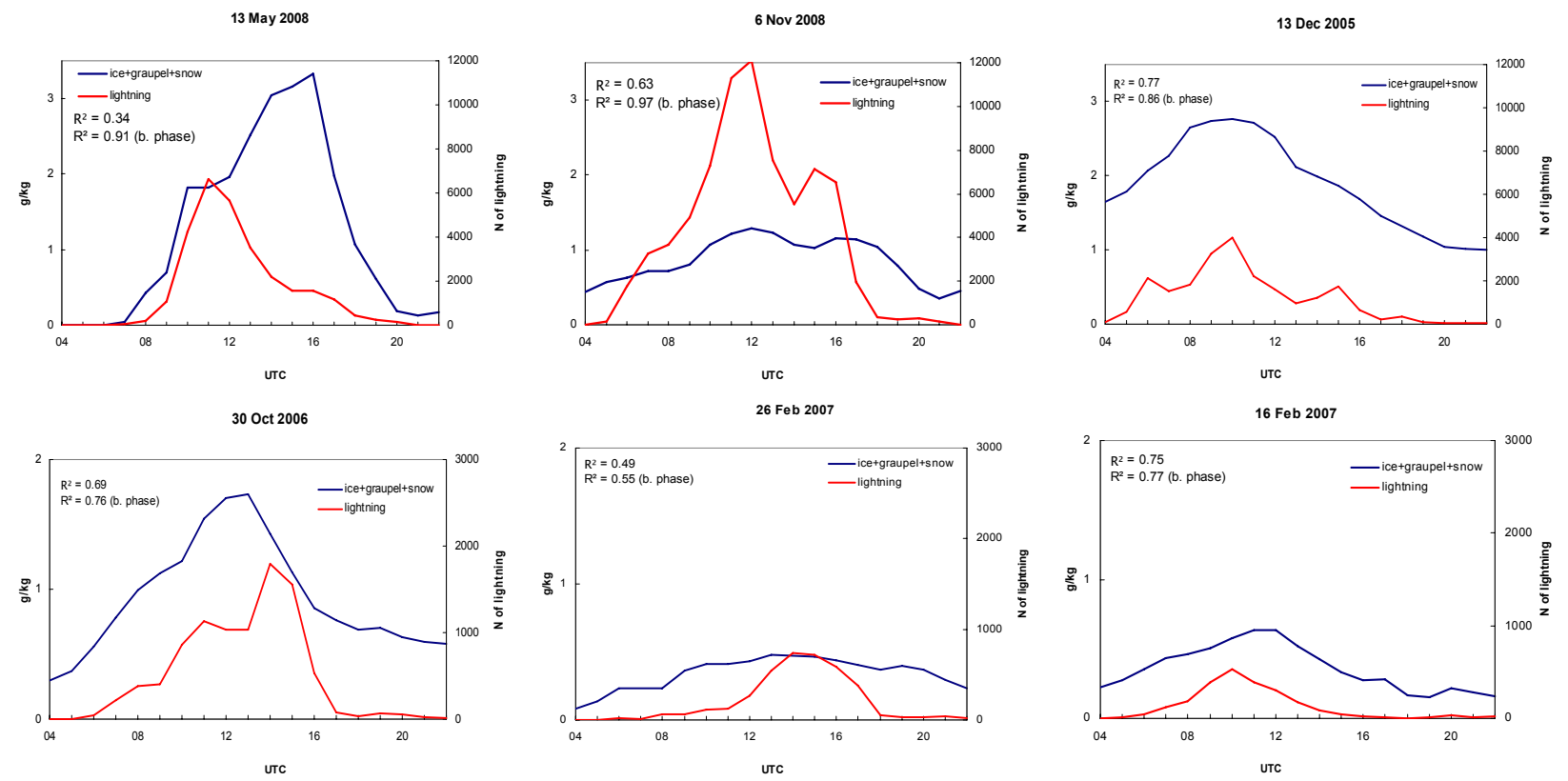

Fig. 3. Temporal evolution diagrams of ice + graupel + snow $(\mathrm{g} / \mathrm{kg})$ and lightning for 6 cases concerning the time period $04: 00 \mathrm{UTC}$ to 22:00 UTC. In the upper left corner the value of $R^{2}$ (R square) between both parameters is given for the same period and for the time period until the maximum of lightning occurrence.
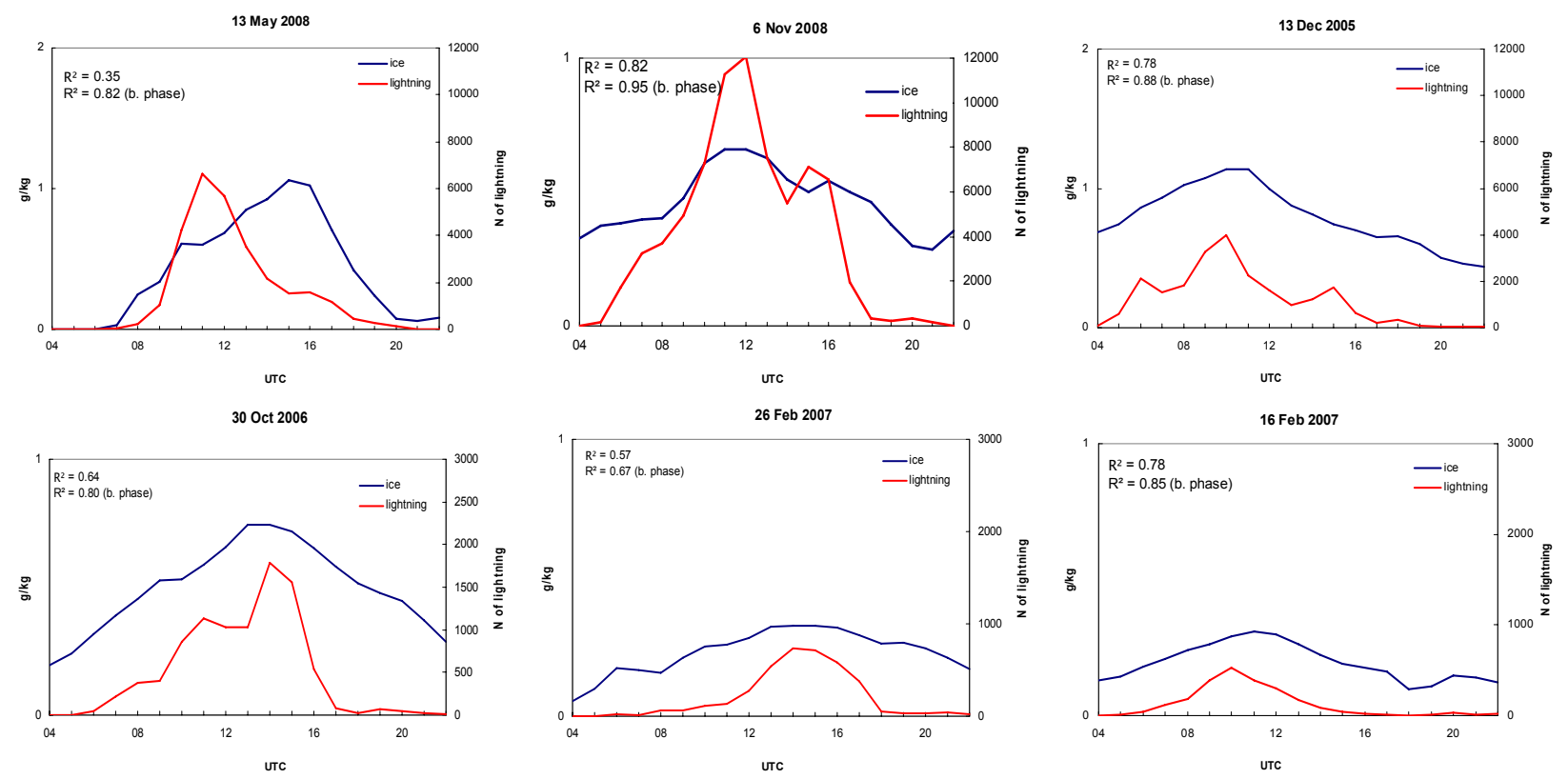

Fig. 4. Temporal evolution diagrams of ice $(\mathrm{g} / \mathrm{kg})$ and lightning for 6 cases concerning the time period 04:00 UTC to 22:00 UTC. In the upper left corner the value of $R^{2}$ (R square) between both parameters is given for the same period and for the time period until the maximum of lightning occurrence.

the time distribution of the sum of lightning within boxes of almost $5^{\circ} \times 5^{\circ}$ (that include the area of maximum lightning activity) is compared to the average integrated mixing ratio of ice + graupel + snow of all model grid points that lie within the selected box. Furthermore, the correlation coefficient $R^{2}$ was calculated for the entire studied time interval of each event (04:00 to 22:00 UTC). As from the analysis of the previous two cases, it was evident that the temporal evolution of the lightning activity with solid hydrometeor concentrations was better correlated during the development phase of each event. The correlation coefficient $R^{2}$ has been also calculated for the period up to the maximum of the observed lightning. 
Figure 3 shows that:

1. There is a good correlation in general between the temporal evolution of the lightning activity with that of the solid (ice+graupel+snow) hydrometeor concentrations. $R^{2}$ varies from 0.34 to 0.77 when the entire time period is considered.

2. The correlation is much better during the development stage of each event with $R^{2}$ varying from 0.55 to 0.91 .

3. During the decaying phase the lightning activity seems to decrease more rapidly than the concentrations of the solid hydrometeors.

Although the correlation coefficient of the number of lightning with the solid hydrometeor concentration is good for each studied case, it does not seem that a general relation between the number of lightning and the solid hydrometeor concentration could be derived.

At this point it is interesting to investigate the correlation of each solid hydrometeor species with the lightning. The analysis showed that the best correlation is found with the concentration of the simulated ice. Indeed, Fig. 4 shows the same analysis as Fig. 3 but for ice only. The correlation coefficient between the temporal evolution of the lightning activity with that of the ice concentration, is better than that when all solid hydrometeors are included, and varies from 0.35 to 0.82 when the entire time period is considered. When the time interval is restricted to the development stage, the calculated $R^{2}$ varies from 0.67 to 0.95 .

In recent studies, Mansell et al. (2005) and Barthe and Pinty (2007) using cloud resolving models, in order to study the electrical structure of idealized convective clouds through different parameterizations, concluded that inductive mechanisms of charge separation play a secondary yet important role. Hence, collisions between graupel - droplets, for example, are crucial for the separation of electric charges; the high mixing ratios of graupel at the lower levels of convective regions result to the necessary for lightning production charge separation. This is in good agreement with our Figs. 1d and $2 \mathrm{~d}$ that show that graupel is the dominant hydrometeor at the lower levels of lightning producing clouds, although there are significant differences between a numerical weather prediction model and cloud resolving models. Barthe and Pinty (2007), suggested also that supercooled water is the key element for the production of graupel, while the presence of other types of hydrometeors, like ice crystals, is also important.

\section{Summary}

The distribution and the number of lightning are related with the presence of ice, the strength of the updraft within the convective clouds as well as their vertical development. The scarcity of direct measurements of microphysical parameters such as ice content of lightning producing clouds, in the region of the Mediterranean, supports the need for the use of spaceborne passive microwave observations for such type of studies. As spaceborne microwave observations, available from low orbiting platforms cannot provide a continuous monitoring of lightning producing systems, but they only provide snapshots of these events (1-2 per day), another possibility is to relate lightning activity with the simulated microphysical parameters provided by weather forecasting models.

For that reason, the present study investigates the possibility of using numerical weather model outputs as proxy for lightning occurrence. Indeed, a number of cases accompanied with strong lightning activity in the central and eastern Mediterranean have been selected. These cases were simulated with the non-hydrostatic MM5 model and the temporal evolution of the lightning activity, observed by ZEUS lightning detection network, has been studied, in relation with the temporal evolution of the simulated convective precipitation, as well as with the concentration of solid (ice + graupel + snow) hydrometeors.

The results do not show a clear relationship between convective precipitation and lightning, as convective precipitation is simulated both before and after the whole period of lightning activity occurrence and also in areas without recorded lightning flashes. On the other hand, a good correlation was found between the temporal evolution of the number of lightning with the profiles of mixing ratio of solid hydrometeors and an approximate temporal coincidence in their maximum. The correlation is increased during the development stage of the events and also the correlation increases when only ice hydrometeors are considered in the comparison.

These results could be expected, as the presence of ice particles is directly related with the phenomenon of lightning, while on the other hand rainfall, even convective, can still be observed in the absence of lightning activity. In order to quantify their qualitative results, the authors are convinced that it is worth to extend this study to a larger number of cases. Further, other techniques could be considered, such as the Lightning Potential Index (LPI) introduced recently by Yair et al. (2009), that measures of the potential for charge generation and separation that leads to lightning flashes in convective thunderstorms.

Acknowledgements. This work has been supported by the EU financed project FLASH (Contract No. 036852). The authors thank the reviewers for their constructive comments.

Edited by: S. Michaelides, K. Savvidou, and F. Tymvios Reviewed by: two anonymous referees 


\section{References}

Barthe, C. and Pinty, J.-P.: Simulation of electrified storms with comparison of the charge structure and lightning efficiency, J. Geophys. Res., 112, D19204, doi:10.1029/2006JD008241, 2007.

Christian, H. J., Blakeslee, R. J., Boccippio, D. J., Boeck, W. L, Buechler, D. E., Driscoll, K. T., Goodman, S. J., Hall, J. M., Koshak, W. J., Mach, D. M., and Stewart, M. F.: Global frequency and distribution of lightning as observed by optical transient detector (OTD), Proc. 11th Int. Conf. on Atmospheric Electricity, NASA, Huntsville, AL, USA, 726-729, 1999.

Defer, E., Lagouvardos, K., and Kotroni, V.: Lightning activity in the eastern Mediterranean region, J. Geophys. Res., 110, D24210, doi:10.1029/2004JD005710, 2005.

Deierling, W. and Petersen, W. A.: Total lightning activity as an indicator of updraft characteristics, J. Geophys. Res., 113, D16210, doi:10.1029/2007JD009598, 2008.

Dudhia, J.: A non-hydrostatic version of the Penn State/NCAR mesoscale model: validation tests and simulation of an Atlantic cyclone and cold front, Mon. Weather Rev.,121, 1493-1513, 1993.

Holt, M. A., Hardaker, P. J., and McClelland, G. P.: A lightning climatology for Europe and the UK, 1990-99, Weather, 56, 290296, 2001.

Hong, S.-Y. and Pan, H.-L.: Nonlocal boundary layer vertical diffusion in a medium-range forecast model, Mon. Weather Rev., 124, 2322-2339, 1996.

Kain, J. S. and Fritsch, J. M.: Convective parameterization for mesoscale models: The Kain-Fritsch scheme. The Representation of Cumulus in numerical models, American Meteorological Society, Meteor. Mon., 46, 165-177, 1993.

Katsanos, D., Kotroni, V., and Lagouvardos, K.: Lightning in the Mediterranean in Relation with Cloud Microphysical Parameters. Lightning: Principles, Instruments and Applications, Springer, 433-446, 2008.

Katsanos, D., Lagouvardos, K., Kotroni, V., and Argiriou, A.: Combined analysis of rainfall and lightning data produced by mesoscale systems in the central and eastern Mediterranean, Atmos. Res., 83, 55-63, 2007a.

Katsanos, D., Lagouvardos, K., Kotroni, V., and Argiriou, A.: Correlation of lightning activity with microwave brightness temperatures and spaceborne radar reflectivity profiles in the Central and Eastern Mediterranean, J. Appl. Meteorol. Clim., 46, 1901-1912, $2007 b$.
Kotroni, V. and Lagouvardos, K.: Lightning occurrence in relation with elevation, terrain slope and vegetation cover in the Mediterranean, J. Geophys. Res., 113, D21118, doi:10.1029/2008JD010605, 2008.

Kotroni, V. and Lagouvardos, K.: Precipitation Forecast Skill of Different Convective Parameterization and Microphysical Schemes: Application for the Cold Season Over Greece, Geophys. Res. Lett., 28(10), 1977-1980, 2001.

Lagouvardos, K. and Kotroni, V.: TRMM and lightning observations of a low-pressure system over the Eastern Mediterranean, BAMS, 88, 1363-1367, 2007.

Lagouvardos, K., Kotroni, V., Betz, H.-D., and Schmidt, K.: A comparison of lightning data provided by ZEUS and LINET networks over Western Europe, Nat. Hazards Earth Syst. Sci., 9, 1713-1717, 2009, http://www.nat-hazards-earth-syst-sci.net/9/1713/2009/.

Mansell, E. R., MacGorman, D. R., Ziegler, C. L., and Straka, J. M.: Charge structure and lightning sensitivity in a simulated multicell thunderstorm, J. Geophys. Res., 110, D12101, doi:10.1029/2004JD005287, 2005

Orville, R. E.: Global distribution of midnight lightning September to November 1977, Mon. Weather Rev., 109, 391-395, 1981.

Pessi, A. T. and Businger, S.: Relationship between Lightning, Precipitation and Hydrometeor characteristics over the North Pacific Ocean, detection with 3-D discrimination of intracloud and cloud-to-ground discharges, J. Appl. Meteorol. Clim., 48(4), 833-848, 2009.

Price, C. and Federmesser, B.: Lightning-rainfall relationships in Mediterranean winter thunderstorms, Geophys. Res. Lett., 33, L07813, doi:10.1029/2005GL024794, 2006.

Rakov, V. A. and Uman, M. A.: Lightning. Physics and Effects, Cambridge University Press, Cambridge, 2003.

Schultz, P.: An explicit cloud physics parameterization for operational numerical weather prediction, Mon. Weather Rev., 123, 3331-3343, 1995.

Sherwood, S. C., Phillips, V. T. J., and Wettlaufer, J. S.: Small ice crystals and the climatology of lightning, Geophys. Res. Lett., 33, L05804, doi:10.1029/2005GL025242, 2006.

Toracinta, E. R. and Zipser, E. J.: Lightning and SSM/I-icescattering mesoscale convective systems in the global Tropics, J. Appl. Meteorol., 40, 983-1002, 2001.

Yair, Y., Lynn, B., Price, C., Kotroni, V., Lagouvardos, K., Morin, E., Mugnai, A., and Llasat, M.-C.: Predicting the potential for lightning activity in Mediterranean storms based on the WRF model dynamic and microphysical fields, J. Geophys. Res., accepted, 2009. 